1 Denning DW, Stevens DA. Antifungal and surgical treatment of invasive aspergillosis: review of 2121 published cases. Rev Infect Dis 1990;12:1147-201.

2 Meunier F, Prentice HG, Ringden O. Liposomal amphotericin B (AmBisome): safety data from a phase $2 / 3$ clinical trial. $\mathcal{f}$ Antimicrob Chemother 1991;28(Suppl B): 83-91.

3 Ellis DA, Neville E, Hall RJC. Subacute massive pulmonary embolism treated with plasminogen and streptokinase. Thorax 1983;38:903-7.

4 Lopez-Berestein G, Body GP, Fainstein V, Keating M, Frankel LS, Zeluff B, et al. Treatment of systemic fungal infections with liposomal amphotericin B. Arch Intern Med 1989;149:2533-6.
5 Chopra R, Blair S, Strang J, Cervi P, Patterson KG, Goldstone AH. Liposomal amphotericin B (AmBisome) in the treatment of fungal infections in neutropenic patients. $\mathcal{F}$ Antimicrob Chemother 1991;28(Suppl B):93-104.

6 Ringden O, Meunier F, Tollemar J, Ricci P, Tura S, Kuse E, et al. Efficacy of amphotericin B encapsulated in liposomes (AmBisome) in the treatment of invasive fungal infections in immunocompromised patients. 7 Antimicrob Chemother 1991;28(Suppl B):73-82.

7 Taylor KMG, Newton JM. Liposomes for controlled delivery of drugs to the lungs. Thorax 1992;47:257-9.

8 Hay RJ. Overview of the treatment of disseminated fungal infections. F Antimicrob Chemother 1991;28(Suppl B):1725 .

\title{
Commentary
}

\section{M Geddes}

These three cases are at first sight completely different, but there is an important common theme. In each instance an unconventional and expensive treatment was given when all else had failed and the results were gratifyingly successful. This begs the question, common to all case reports, whether they are illustrative and helpful for the management of other patients, or whether they simply represent an amazing coincidence which has been given spurious respectability by being published. The clinical teams should be congratulated on their ingenuity and persistence, but did the management change actually contribute to the improvement or was it simply a way of structuring time (at considerable expense) until nature did the job?

The case presented by Codispoti et al (pp 1317-9) describes the use of extracorporeal membrane oxygenation (ECMO) to support a patient dying of pneumococcal pneumonia until treatment was effective. The key question here is whether or not she could have survived the six days of ECMO support with conventional ventilation. The reason given for starting ECMO was that the haemodynamic and ventilatory parameters were considered incompatible with survival. If we assume this judgement to be correct, then ECMO undoubtedly saved her life. Previous studies of ECMO in randomised trials have shown no benefit, but the failure of a treatment for a randomised group does not mean that the treatment could never be helpful to anyone. The lesson from this report is that ECMO should be considered as a last ditch means of ventilatory support when there are very good grounds to predict eventual recovery. Such cases are probably very few, and it is essential that this report is not used as an argument for an expensive escalation in preterminal treatment for those patients with no hope of survival.

The second report by Touleimat et al (pp 1319-21) suggests that instillation of DNase via a bronchoscope to an area of the lung subject to recurrent collapse from sputum retention is worthwhile. The description of the results "... rapid dissolution of sputum and opening of the orifice..." is more in line with reporter enthusiasm than enzyme kinetics. Also, at first sight it is difficult to see how a single DNase treatment with clearing of sputum could have a lasting effect when aspiration of the plug previously did not. It is conceivable, however, that DNase allowed clearance of more peripheral airways and thus promoted better ventilation and clearance to prevent subsequent sputum plugging. DNase is expensive for chronic treatment but a single dose is not, and this report certainly suggests a possible indication for a new drug over and above that which has been established in clinical trials. It is interesting to speculate whether nebulised DNase would have been equally successful, avoiding repeat bronchoscopies with the cost and inconvenience involved.

The final case report described by Purcell and Corris on pp 1321-3 is the most difficult to believe. In this, nebulised liposomal amphotericin apparently sterilised the pleural space when intrapleural instillation of amphotericin had failed. Even if the patient did have a large bronchopleural fistula, this still sounds a singularly inefficient way of getting a drug into this compartment. Either there is some additional therapeutic benefit from putting the drug into a liposome, which is highly unlikely, or the itraconazole that was given at the same time was actually responsible for the improvement. Either way the main interest of the report, as the authors point out, is that the liposomal form of amphotericin did not provoke asthma when the conventional form had done so, and there may well be other situations in which liposomal amphotericin by nebuliser would be worth considering.

Taken together, these reports are useful for clinicians to remember when they have a very difficult case on their hands. It is, however, essential that these approaches are applied intelligently and are not used as an excuse for mindless expense. Controlled clinical trials are valuable for common problems but cannot address rare and difficult management issues such as these. This is the true value of case reports.

\footnotetext{
Royal Brompton Sydney Street, UK D M Geddes
} 